\author{
P.P. Maksimyak, C.Yu. Zenkova, V.M. Tkachuk
}

\title{
Carbon Nanoparticles. Production, properties, perspectives of use
}

\author{
Chernivtsi National University, Chernivtsi, 58012, Ukraine, k.zenkova@chnu.edu.ua
}

\begin{abstract}
The work is devoted to the study of the optical properties of carbon nanoparticles synthesized by the method developed during our experimental studies. The optimal conditions for the creation of carbon nanostructures with predetermined properties are defined. Nanoparticles of the size of about $100 \mathrm{~nm}$ were obtained, the maximum of absorption of which is localized at wavelengths in the violet-blue region of the spectrum, while the maximum of luminescence - in the green region of the spectrum. The assumption is made about the possibility of using the obtained particles for correlation diagnostics of optical speckle fields.

Keywords: graphene nanoparticles, luminescence, absorption, speckle field.
\end{abstract}

Received 01.10.2019; accepted for publication 15.03.2020.

\section{Introduction}

The relevance of the study of the carbon nanomaterials properties is related to the unique features of these structures, namely, their specific optical manifestations, luminescence in the visible region of the spectrum, anomalous absorption, chemical passivity, and non-aggressiveness to biological systems.

According to the existing classification [1], fluorescent nanoparticles are divided into four classes, among which carbon nanoparticles are notable due to their size of about one hundred nanometers. Such structures are rather attractive because they exhibit luminescence at wavelengths in the yellow-green and red regions of the spectrum. Here, we outline carbon nanoparticles with regulated emissions, since classical traditional approaches typically allow the formation of particles whose emission is limited by the blue region of the spectrum.

The analysis of the methods [2] for creating carbon particles distinguishes between top-down and bottom-up methods. In the top-down methods, carbon particles are typically formed from specially selected carbon materials correspondingly to the method of creation. At the same time the bottom-up one works with a subset of molecular precursors that allows obtaining a particle in one cycle.

Top-down methods include laser ablation and laser based synthesis, oxidation, electrochemical release, while the bottom-up ones include pyrolysis, ultrasound assisted synthesis, microwave synthesis, electrochemical synthesis, synthesis without physical treatment, hydrothermal synthesis. Without considering the disadvantages and advantages of each method, we chose bottom-up method with hydrothermal synthesis of carbon nanoparticles to produce nanoparticles of about hundreds of nanometers in size. The properties of the created particles [3-6] significantly depend on the surface structure of the shell and on the structure of the nucleus, the location of polar groups, and their active centers. The mechanism of carbon nanoparticles synthesis, the nature of the reagents, and the peculiarities of the electronic transitions of the basis of the substance determine the set of photo-induced redox reactions of electron exchange between the active centers of donors and acceptors, and therefore the properties of the obtained nanoparticles. The method we choose allows us to isolate nanoparticles with stabilized carboxyl and amino groups, with predetermined optical properties.

Much research work has been devoted to the study of carbon [7-9]. But the isolation and creation of carbon structures, which are predetermined and whose properties are foreseen, is a separate task that was successfully solved in the course of the work, and is an intermediate stage of the problem of the diagnostic nature of the analysis of random optical fields.

Therefore, the purpose of this work is to develop and extend the technique of creating carbon nanoparticles with 
predictable properties, namely, controlled sizes, strong optical absorption at wavelengths of $405 \mathrm{~nm}$, and emission in the visible region at wavelengths of about $530 \mathrm{~nm}$. The creation of such particles will allow the diagnostics of speckle fields, by moving these particles along the intensity gradient by optical fluxes with their localization in the singular regions. Such diagnostic approaches extend the existing correlation-singular methods of processing complex inhomogeneous optical fields [10-15].

\section{Fundamentals of approaches for obtaining carbon nanoparticles. Size estimation}

Among the existing techniques for the creation of carbon nanoparticles [8], in our experimental approach, as it was previously mentioned, the bottom-up method is used. Citric acid $(0.2 \mathrm{~g})$ and urea $(0.2 \mathrm{~g})$ were selected as reagents [3] in equal proportions. In a plastic tube, the mixture is dissolved in $5 \mathrm{ml}$ of distilled water to form a clear solution. Then the solution is poured into a porcelain crucible (10 $\mathrm{ml}$ in volume) and has been heated in the oven at $\mathrm{t}=190^{\circ} \mathrm{C}$ for 2 hours. The heat treatment results in the formation of a precipitate consisting of carbon nanoparticles. After cooling, the latter is dissolved in 10 $\mathrm{ml}$ of distilled water within 3 hours. Particles dissolved in water are removed into a separate flask. To obtain an aqueous solution of carbon nanoparticles of the same size, a magnetic stirrer MicroMed 35-40 minutes is used. In 2 hours at rest after mixing, a solution is obtained, which is used for further centrifugation to separate particles of different sizes.

Eight centrifuge tubes are used in the centrifugation process. The centrifugation frequency can vary from 500 rpm to $13000 \mathrm{rpm}$. Centrifugation time is also regulated. In the first stage, the centrifugation frequency was set to $500 \mathrm{rpm}$, the time of centrifugation varied from 1 to 8 minutes. During this time interval the composition of the solutions does not change visually, i.e. the deposition of particles did not occur. The next step consisted in mixing the solutions in one container for stirring with a MicroMed stirrer and continuing the centrifugation of the resulting solution, starting from 9 minutes. This is the time period of centrifugation that enabled to obtain a precipitate of large particles and a residual working solution with suspended particles. Obtaining a precipitate allows to conclude the separation of carbon particles in the residual liquid. The time of centrifugation in the production of particles was being increased. To determine the end time when the concentration of nanoparticles in the working solution did not change with increasing centrifugation time, optical approaches for estimating the optical density of the solutions were used.

The optical density was measured using the setup shown in Fig. 1. The main components of the setup are a filament lamp of iodine cycle with stabilizer (1), monochromator MUM 01 (6), cuvette with prepared sample (7) and photodiode FD-288B (8). The use of a stabilizer allows you to maintain the voltage level and to ensure the stability of the radiation intensity of the incident beam. Radiation of a filament lamp of iodine cycle is in the wavelength range of 90-2200 nm, from which the monochromator emits a working wavelength corresponding to the maximum absorption of the obtained carbon nanoparticles (405 nm) [1]. The the FD-288V germanium photodiode acts as a radiation receiver, with a working wavelength range of 190-1100 nm, a dark current of $40 \mathrm{nA}$.

Sample preparation for optical density measurement was as follows. The resulting working solution for different time intervals of centrifugation was dried; to compare the set of samples obtained, the latter were dissolved in an equal volume of distilled water $(2 \mathrm{ml})$.

The optical density was estimated as $D=-\ln \left({ }^{I_{\tau}} / I_{0}\right)=k l$, where $I_{\tau}-$ the intensity of the transmitted radiation, $I_{0}$ - the intensity of the radiation incident on the cuvette, $k$ - the extinction index, $l$ - the thickness of the cuvette $(10 \mathrm{~mm})$.

For example, the results of calculations of the optical density for the centrifugation frequency of $500 \mathrm{rpm}$ (405 $\mathrm{nm}$ ) for different centrifugation times are shown in Fig. 2.

In particular, for the centrifugation frequency of 500 rpm (Fig. 3), at time interval from 9 to 20 minutes, the particle concentration increased, respectively, with the decrease in the signal at radiation receiver (8) (Fig. 2). The increase in particle concentration is accompanied by an increase in the extinction of the samples and a corresponding decrease in the intensity of the transmitted radiation. This change results in the increase in the optical density.

From the 21 st minutes, the signal at the output of the sample remained constant. The optical density of the

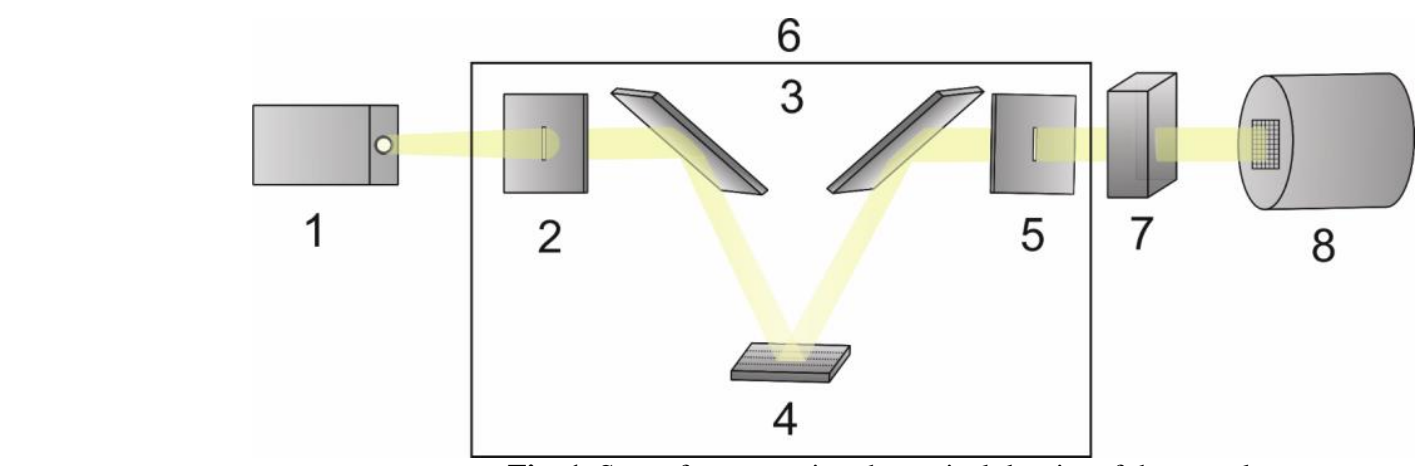

Fig. 1. Setup for measuring the optical density of the samples:

1 - filament lamp of iodine cycle with a stabilizer,

2 - the entrance slit, 3 - the system of rotating mirrors, 4 - the diffraction mirror, 5 - the output slit, 6 - monochromator MUM-01, 7 - cuvette with the sample, 8 - radiation receiver. 
samples did not change, which enables to conclude about the time, which under the selected conditions determines the formation of a final solution with working nanoparticles.

To check and control the conditions found, the working solutions obtained for different time intervals of centrifugation are merged into one tank, then this solution is mixed with the MicroMed stirrer for further centrifugation for 21 minutes with subsequent control of the optical density. The result of the optical density is confirmed, thus a conclusion can be made that for 500 $\mathrm{rpm}, 21$ minutes is the exact time that reproduces the condition of obtaining carbon nanoparticles. It was the obtained working solutions that we used to study the

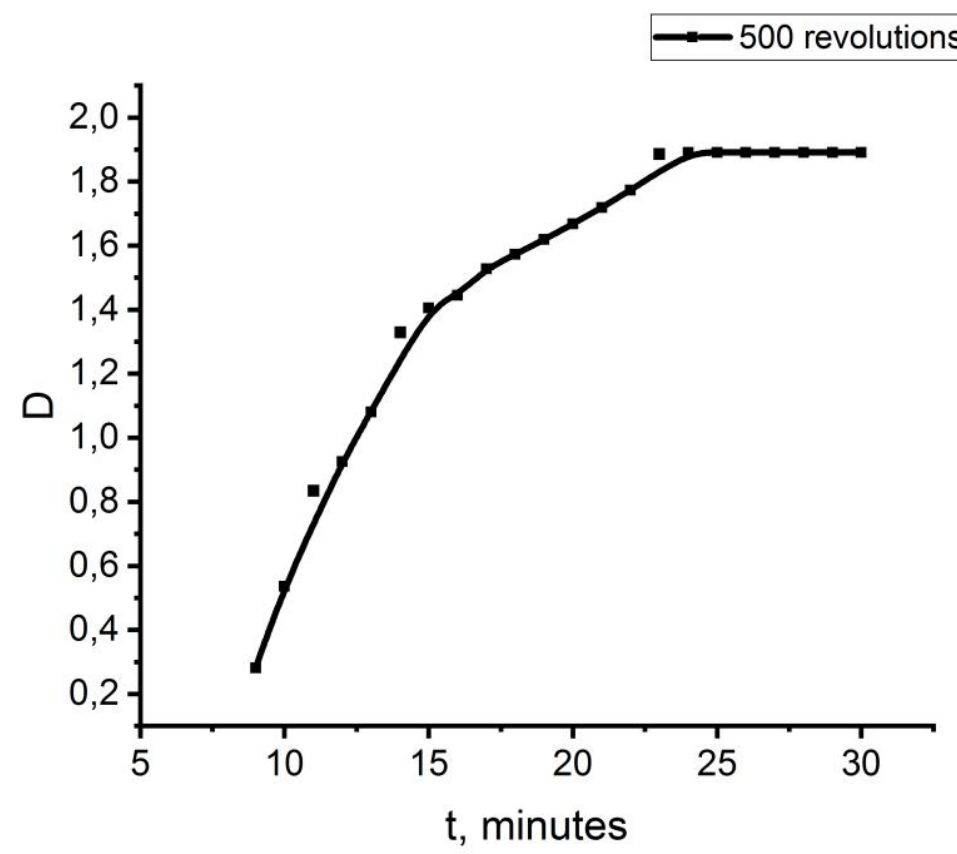

Fig. 2. Dependence of the optical density of the samples on the centrifugation time for centrifugation frequency of $500 \mathrm{rpm}$.

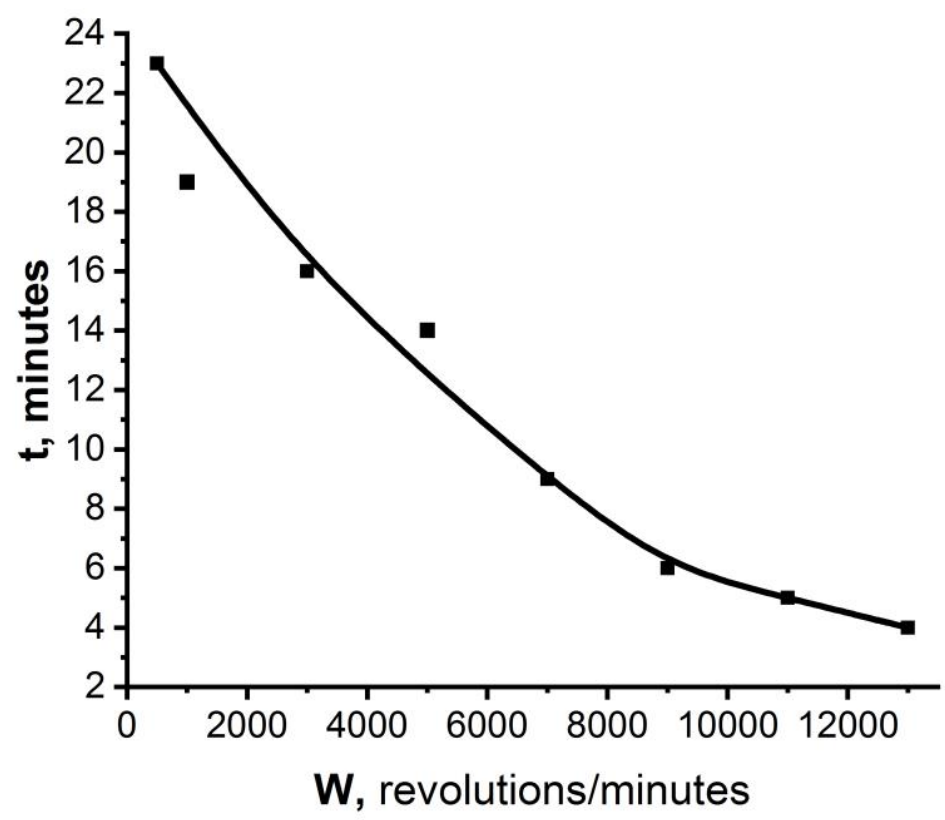

Fig. 3. Dependence of the deposition time of the particles on the rotation speed of the centrifuge. 
luminescence spectra.

Working solutions for different centrifugation frequencies are obtained and controlled similarly. It should be noted that the gradual increase in the centrifugation frequency causes a decrease in the time at which a constant (unchanged) concentration of carbonic particles in the working solution is observed (Fig. 3).

The obtained carbon particles, which are suspended in aqueous solutions, are subject to careful size measurement and analysis. In particular, for the particle size measurements an optical setup was used consisting of a biological immersion microscope Biolam 70 and a CCD camera (DCM-500 SCOPE Video Glass). The video eyepiece is supported on OS Windows 2000 / XP / 2003/7 (32 and 64 bit). ScopePhoto software was used. To measure the size of the nanoparticles, the software scale was calibrated. At this stage it was possible to centrifugation frequency from $500 \mathrm{rpm}$ to $515 \mathrm{~nm}$ for a centrifugation frequency of $4000 \mathrm{rpm}$.

For more accurate measurements, atomic force microscopy approaches were used. Specially prepared specimens [16] were carefully analyzed, which allowed the determination of carbon nanoparticle sizes up to $100 \mathrm{~nm}$ for centrifugation frequency of $13,000 \mathrm{rpm}$. It is the aqueous solutions of such carbon nanoparticles that will enable to diagnose optical fields, to observe the movement of these particles by internal optical fluxes [1719], and to perform spatial-frequency processing and reproduction of phase distributions over a spatial recorded picture, visualized by luminescence. The mobility of the investigated objects, the spatial displacement of optical fields can be studied through the analysis of the skeleton of the optical field, the reproduction of phase information using mathematical processing of Hilbert transform, in particular [10-15].
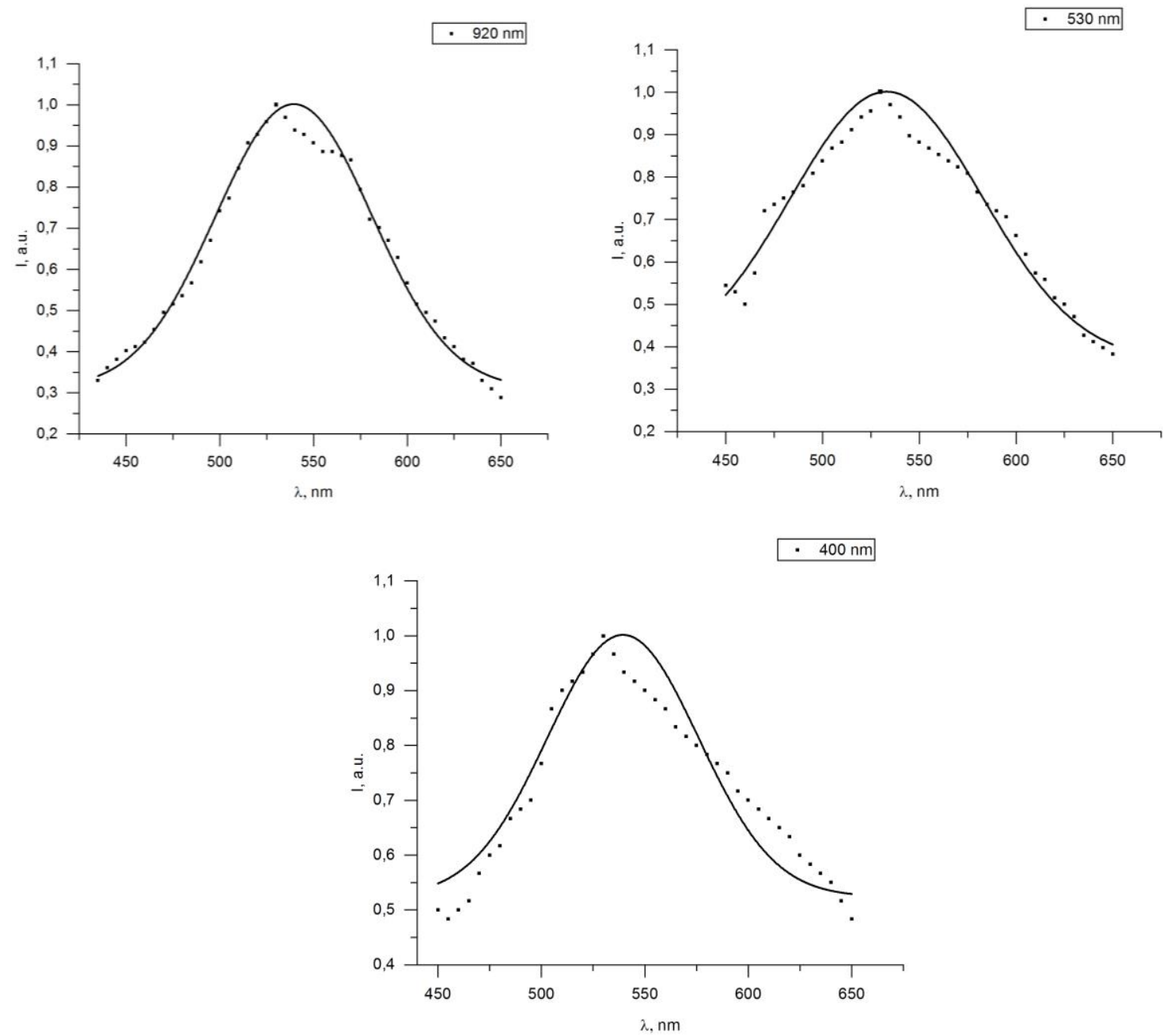

Fig. 4. Luminescence spectra of carbon nanoparticles. The insets indicate the preferred size of particles obtained during the experiment. The dots in the figures indicate recorded experimentally obtained values 


\section{Luminescence of synthesized carbon nanoparticles}

Visualization of the skeleton by carbon nanoparticles becomes possible if the luminescence of the nanoparticles can be fixed. For that the results of measuring the luminescence of the obtained carbon nanoparticles on the modificated setup, the base scheme of which is shown in Fig. 1, are presented. An additional optical element (not shown in the figure) of such a modified setup is a light filter UV (CФ -12) with a transmission band of 410 - 650 $\mathrm{nm}$, which is located behind the monochromator to eliminate the radiation scattered from the object. The maximum radiation of the filter $(405 \mathrm{~nm})$ corresponds to the maximum absorption of carbon nanoparticles.

The sample under study is placed in front of the monochromator. In order to avoid the manifestation of temperature changes, the temperature regime and the exposure time are controlled. The sample is prepared in a special way: to measure the luminescence of aqueous solutions of carbon nanoparticles obtained for different centrifugation frequency under the same conditions, the optical density of the solutions is estimated. The uniformity of optical density values, that is, the equal absorption of solutions, is chosen as the criterion of readiness of the samples for measuring the luminescence.

Figure 3 shows the luminescence spectra for the samples obtained for centrifugation frequency of $500 \mathrm{rpm}$, $5000 \mathrm{rpm}$, and $9000 \mathrm{rpm}$ and carbon particles size of about $920 \mathrm{~nm}, 530 \mathrm{~nm}, 400 \mathrm{~nm}$ correspondingly. The luminescence maximum is achieved at the wavelength of $530 \mathrm{~nm}$ (Fig. 4).

The radiation of carbon nanoparticles at this wavelength is also used to study complex optical fields. Carbon nanoparticles move to the regions of optical vortexes (singularities) and intensity minimum [20-23].

Gradient optical forces determine the movement of carbon nanoparticles in the areas where the localization of nanoparticles occurs. The optical speckle field is modeled by a set of spatially distributed carbon nanoparticles in the areas of the intensity gradient, thereby reproducing the structure (skeleton) base of the optical field, followed by mathematical processing of this structure, restoring the phase map in real time and obtaining information about the state of the object.

A distinctive feature of this approach using carbon structures is that the probability of error in the diagnostics of amplitude zeros is reduced, since gradient optical forces are directly related to the magnitude of internal energy flows and their spatial distribution in the analyzed speckle field.

The structure of the optical speckle field is visualized with the following fixation of this structure by a CCD camera. The prospects of studying optical fields with carbon nanoparticles prove to be a promising mechanism for conducting structural analysis of speckle fields with the recovery of phase information about an object, the reproduction of information about spatial changes in the structure of nano- and macroobjects.

\section{Conclusions}

As a result of the research the carbon nanoparticles of the predicted sizes of about $100 \mathrm{~nm}$ with predetermined properties, including the luminescence maximum in the green region of the spectrum at wavelength of $530 \mathrm{~nm}$ were obtained. It is these properties that enable to use the obtained particles for the correlation diagnostics of optical speckle fields, to reproduce the phase map of an object, and then - the amplitude distributions of micro- and macroobjects, the states of which change over time.

The work was performed within the specific project "Resurs" KC063.18 "Development of chemical composition and technological decisions for the manufacture of railway wheels for different application and their maintainability" of the NAS of Ukraine.

Maksimyak P.P. - Professor, Doctor of Ph.D., Acting Head of the Department of Correlation Optics;

Zenkova C.Yu. - Doctor of Science (MSc), Professor of the Department of Optics and Printing and Printing;

Tkachuk V.M. - Postgraduate student of the Department of Optics and Printing.

[1] Y. Wang, A. Hu, Journal of Materials Chemistry C 34, (2014) (https://doi.org/10.1039/C4TC00988F).

[2] I.Y. Goryacheva, A.V. Sapelkin, G.B. Sukhorukov, Trends in Analytical Chemistry (2017), (https://doi.org/10.1016/j.trac.2017.02.012).

[3] C.J. Reckmeier, J. Schneider, A. S. Susha, and A. L. Rogach, Optics Express 24(2), A312 (2016).

[4] S.K. Pal, Carbon 88, 86 (2015) (https://doi.org/10.1016/j.carbon.2015.02.035).

[5] L. Ge, N. Pan, J. Jin, P. Wang, G. E. LeCroy, W. Liang, L. Yang, L. R. Teisl, Y. Tang, and Ya-P. Sun,J. Phys. Chem. C, 122(37), 21667 (2018) (https://doi.org/10.1021/acs.jpcc.8b06998).

[6] R. Wang, K.-Q. Lu, Zi-R. Tang and Yi-J. Xu, Journal of Materials Chemistry A. 8(1-3), 19 (2013) (https://doi.org/10.1039/C8RA04599B).

[7] A.P. Demchenko, Introduction to Fluorescence Sensing (Second Edition. Springer International Publishing, 2015).

[8] G. Hong, Sh. Diao, A. L. Antaris, and H. Dai, Chem. Rev., 115(19), 10816 (2015) (https://doi.org/10.1021/acs.chemrev.5b00008). 
[9] Y. Choi, Y. Choi, Oh-H. Kwon, and B.-Su Kim, Chemistry - An Asian Journal (2018) (https://doi.org/10.1002/asia.201701736).

[10] C.Yu. Zenkova, M.P. Gorsky, P.A. Ryabiy, Optica Applicata 45(2), 139 (https://doi.org/10.5277/oa150201).

[11] C.Yu. Zenkova, M.P. Gorsky, P.A. Ryabyj, Optical Memory and Neural Networks (Information Optics) 24(4), 303 (2015) (https://doi.org/10.3103/S1060992X15040074).

[12] C.Yu. Zenkova, M.P. Gorsky, P.A. Ryabiy, Romanian Reports in Physics 67(4), 1401 (2015).

[13] C. Yu. Zenkova, M. P. Gorsky, P. A. Ryabiy, and A. O. Angelskaya, Appl. Opt. 55(12), B78 (2016) (https://doi.org/10.1364/AO.55.000B78).

[14] C.Yu. Zenkova, M.P. Gorsky, P.A. Ryabiy, Optica Applicata 46(1), $153 \quad$ (2016) (https://doi.org/10.5277/oa160114).

[15] C.Yu. Zenkova, M.P. Gorsky, P.A. Ryabyi, Proc. SPIE, 9258, 92582B (2015).

[16] M.V. Nohovitsyna, Ye.P. Neustroev, Ye.K. Burtseva, A.P., Prokop'ev, Actual problems of radiophysics: International Conference (Tomsk, 2017), p.262 (in Russian).

[17] O.V. Angelsky, M.P. Gorsky, P.P. Maksimyak, A.P. Maksimyak, S.G. Hanson, C.Yu. Zenkova, Optics Express 19(2), 660 (2011) (https://doi.org/10.1364/OE.19.000660).

[18] C.Yu. Zenkova, M.P. Gorsky, P.P. Maksimyak, A.P. Maksimyak, Applied Optics 50(8), 1105 (2011) (https://doi.org/10.1364/AO.50.001105).

[19] A.Ya. Bekshaev, O.V. Angelsky, S.V. Sviridova, C.Yu. Zenkova, Advances in Optical Technologies 723901 (2011) (https://doi.org/10.1155/2011/723901).

[20] O.V. Angelsky, P.P. Maksimyak, T.O Perun, Optics Letters 18(2), $90 \quad$ (1993) (https://doi.org/10.1364/OL.18.000090).

[21] O.V. Angelsky, A.Ya. Bekshaev, P.P. Maksimyak, A.P. Maksimyak, S.G. Hanson, Optics Express 26(11), 13995 (2018) (https://doi.org/10.1364/OE.26.013995).

[22] O.V. Angelsky, P.P. Maksymyak, C.Yu. Zenkova, S.G. Hanson, D.D. Ivanskyi, Journal of Biomedical Optics 24(5), 055002 (2019) (https://doi.org/10.1117/1.JBO.24.5.055002).

[23] O.V. Angelsky, Y.A. Ushenko, A.V.Dubolazov, O.Yu. Telenha, Advances in Optical Technologies 130659 (2010).

\section{П.П. Максимяк, К.Ю. Зенкова, В.М. Ткачук \\ Вуглецеві наночастинки. Виготовлення, властивості, перспективи використання}

\footnotetext{
Чернівецький національний університет імені Юрія Федьковича, Чернівиі, 58012; k.zenkova@chnи.еdu.иа,

Робота присвячена вивченню оптичних властивостей карбонових наночастинок, синтезованих за методикою, розвинутою в ході проведених нами експериментальних досліджень. Визначено оптимальні умови створення вуглецевих наноструктур з наперед визначеними властивостями. Отримано наночастинки до розмірів порядка 100 нм, максимум поглинання яких локалізований на довжинах хвиль у фіолетовосиній області спектра, а максимум люмінісценції у зеленій області спектра. Зроблено припущення про можливість використання отриманих частинок для кореляційної діагностики оптичних спекл-полів.

Ключові слова: графенові наночастинки, люмінісценція, поглинання, спекл поле.
} 